\title{
Retrieval of retained pigtail in the liver
}

\author{
Manthreshwar Premkumar, George K Chiramel, Shyamkumar N Keshava \\ Department of Radiology, Christian Medical College, Vellore, Tamil Nadu, India
}

Correspondence: Dr. Shyamkumar N Keshava, Department of Radiology, Christian Medical College, Ida Scudder Road, Vellore - 632004 ,

Tamil Nadu, India. E-mail: aparna_shyam@yahoo.com

\section{Abstract}

The incidence of catheter breakage during percutaneous image-guided treatment of liver hydatid is very rare. A "telescoping" technique was used to retrieve the broken pigtail in this case report. Alternative options for pigtail retrieval are briefly discussed.

Key words: Hydatid cyst liver; pigtail; retrieval; telescoping

\section{Introduction}

Hydatid disease is a worldwide zoonosis produced by the larval stage of the Echinococcus tapeworm. Hydatid disease primarily affects the right lobe of the liver and typically demonstrates characteristic imaging findings. ${ }^{[1]}$ However, there are many potential local and systemic complications. Chest radiography, ultrasound (US), computed tomography, and magnetic resonance imaging (MRI) are all useful in evaluating hydatid disease. The primary treatment technique of hydatid cysts is surgery, which is an invasive method. ${ }^{[2]}$ Therapeutic options for cystic lesions include surgical resection or unroofing, PAIR [percutaneous puncture, aspiration, injection, reaspiration], and percutaneous sclerotherapy. ${ }^{[3]}$ We describe an extremely rare complication and its management during image-guided percutaneous sclerotherapy of the hydatid cyst.

\section{Case History}

A 27-year-old lady was admitted with complaints of abdominal discomfort, dyspepsia, and occasional fever for past one year. Her general and other systemic examinations were normal. Frontal chest radiograph was unremarkable.

\begin{tabular}{|l|l|}
\hline \multicolumn{2}{|c|}{ Access this article online } \\
\hline Quick Response Code: & \\
\cline { 1 - 2 } & Website: \\
& www.ijri.org \\
\cline { 2 - 3 } & DOI: \\
& 10.4103/ijri.IJRI_97_20 \\
\hline
\end{tabular}

US abdomen demonstrated a well-defined cystic lesion in the right lobe of the liver measuring approximately $6 \mathrm{~cm}$ in diameter [110 cc in volume] with a trilaminar membrane and multiple daughter cysts within [Figure 1A]. Contrast enhanced computed tomography (CECT) showed a well-defined rounded, hypodense lesion measuring $6 \mathrm{~cm}$ in diameter with minimal wall enhancement seen predominantly in the segment 7 of the liver with focal thickening at the superior aspect of the wall of lesion. The lesion also demonstrated hypodense foci corresponding to daughter cysts as seen on the US [Figure 1B]. MRI showed a well-defined T2W hyperintense lesion in the right lobe of the liver [segment 7] with multiple internal septations [Figure 1C].

She was started on tablet Albendazole $400 \mathrm{mg}$ twice daily orally for 4 weeks, following which percutaneous sclerotherapy with absolute alcohol was planned. Hydatid cyst in the right lobe of the liver was approached with a 18G Trocar needle [Cook Medical, Bloomington, IN, US] under US guidance. An Amplatz guide wire [0.035 in $\times 75 \mathrm{~cm}]$ was passed into the hydatid cyst through the aspiration needle. The tract was dilated with a 6 Fr dilator. A 6 Fr

This is an open access journal, and articles are distributed under the terms of the Creative Commons Attribution-NonCommercial-ShareAlike 4.0 License, which allows others to remix, tweak, and build upon the work non-commercially, as long as appropriate credit is given and the new creations are licensed under the identical terms.

For reprints contact: WKHLRPMedknow_reprints@wolterskluwer.com

Cite this article as: Premkumar M, Chiramel GK, Keshava SN. Retrieval of retained pigtail in the liver. Indian J Radiol Imaging 2020;30:376-8.

Received: $16-F e b-2020$ Accepted: 13-May-2020

Revised: 09-Apr-2020 Published: $15-$ Oct-2020 


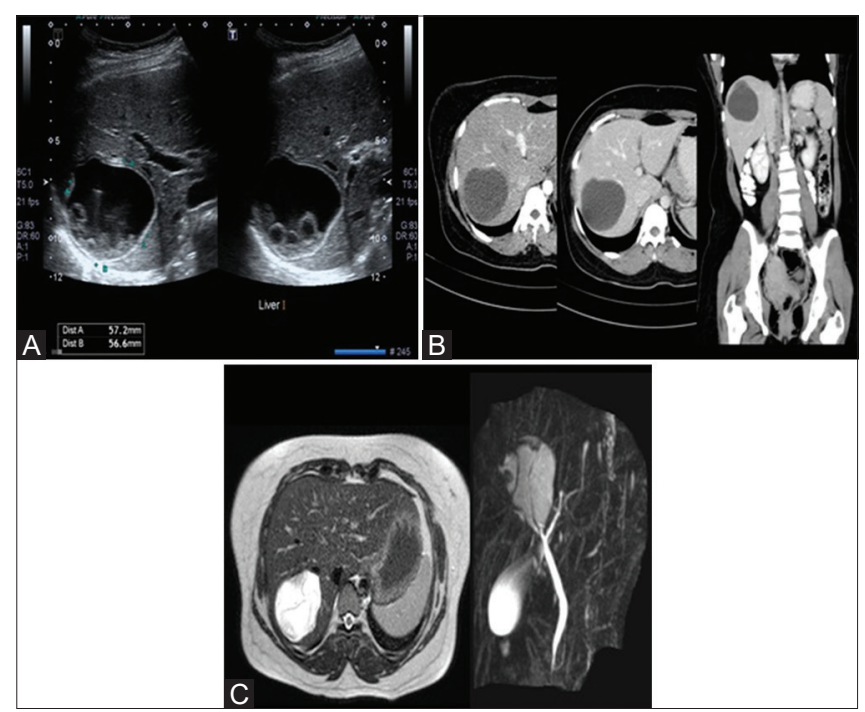

Figure 1 (A-C): (A): US abdomen and pelvis demonstrate a well-defined cystic lesion in the right lobe of the liver with a trilaminar membrane and multiple daughter cysts within (B): CECT shows a well-defined hypodense cystic lesion with mildly enhanced wall seen predominantly in segment 7 of the liver with focal thickening at the superior aspect of the wall of lesion. The lesion also demonstrates hypodense foci corresponding to daughter cysts seen on USG. (C): MRI showed a well-defined T2W hyperintense lesion in the right lobe of the liver (segment 7) with multiple septations within the lesion

Pigtail catheter was placed into the cyst over the wire. Approximately $45 \mathrm{ml}$ of the cyst fluid was aspirated. The fluid was clear. The fluid sample was sent for bilirubin analysis, which was $0.37 \mathrm{mg} / \mathrm{dL}$. Microscopic examination had shown scolices and individual hydatid hooklets. Approximately $15 \mathrm{ml}$ [one- third of the aspirate volume] of absolute alcohol was injected into the cyst through the pigtail catheter.

Once alcohol was injected, Amplatz guide wire was again inserted through the pigtail and pigtail was ready to be removed. While removing, the inner half of the pigtail detached and was retained within the liver [Figure 2A]. However, the guide wire was still in place, coaxially within the detached distal fragment of the pigtail catheter.

As part of the pigtail remained within the liver parenchyma, it was initially thought to push the broken part of pigtail into the hydatid cyst over the guide wire using a $6 \mathrm{~F}$ dilator. A 6F vascular sheath dilator was used. During this attempt, the tip of dilator telescoped inside the broken pigtail. When the dilator was pulled out, the broken piece of the pigtail was also retrieved along with it [Figure 2B]. US of the liver showed no retained pigtail fragment inside. The broken segment of the pigtail was physically examined outside, which matched well with the other piece of the pigtail. The patient had an uneventful course and was discharged the following day.

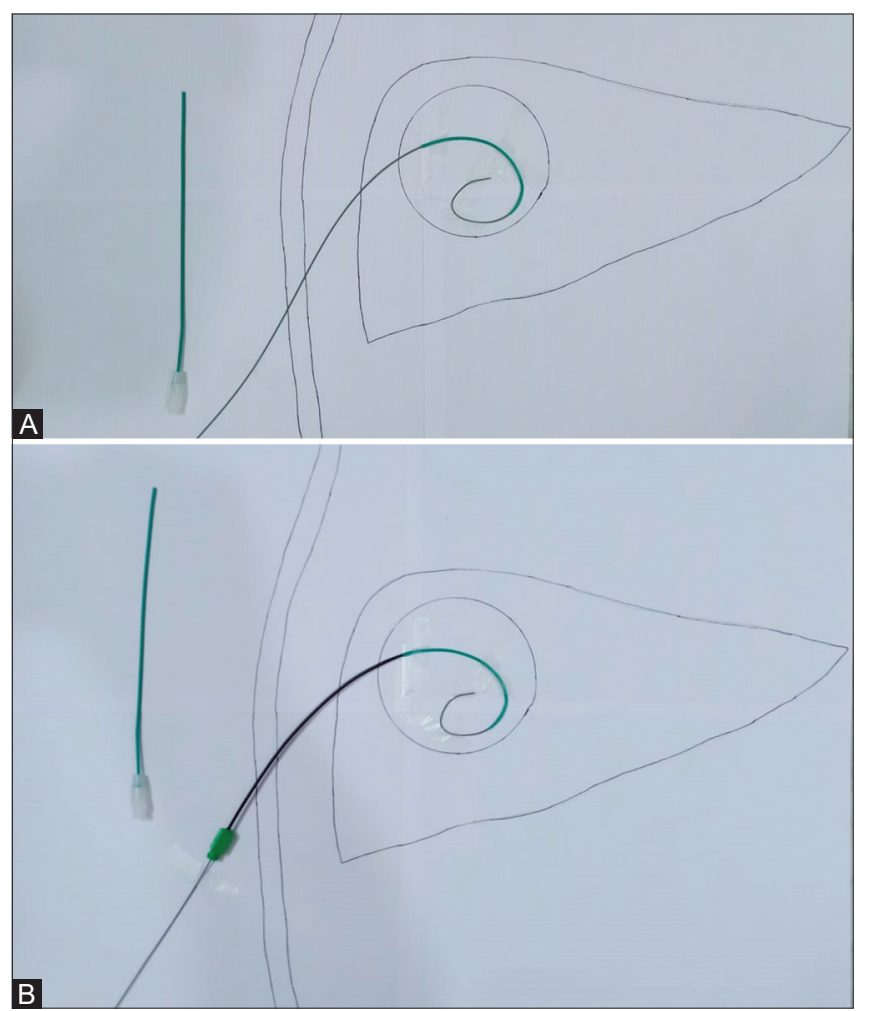

Figure 2 (A and $\mathbf{B})$ : $(\mathrm{A})$ : Schematic image of the proximal and distal broken portion of the pigtail catheter along with the guide wire. (B): Schematic image showing the "telescoped" distal portion of the dilator into the broken pigtail

\section{Discussion}

During alcohol sclerotherapy through a pigtail, one should be aware of this potential complication of breakage of pigtail. Catheter breakdown during percutaneous sclerotherapy using alcohol has previously been described by Amalou et al. ${ }^{[4]}$ In our case, we could not find the exact reason for the breakage of the catheter. Possibility of alcohol reacting with the pigtail material may be considered. Although Pigtail is an inert substance, there could be minimal chance of adverse reaction later in life if left in situ like granuloma formation.

The technique of "telescoping" in this case, albeit a serendipitous one, facilitated the complete retrieval of the pigtail. It is likely that the longer tapered tip of a vascular dilator compared to a regular tract dilator snuggly fitted between the Amplatz guide wire and the broken piece of the pigtail. The alternate options of retrieval of the pigtail catheter were snaring or surgery. ${ }^{[5]}$

\section{Conclusion}

We describe a simple technique of "telescoping" by inserting a vascular sheath dilator into the broken pigtail over a guide 
wire, which was successful in retrieving a broken pigtail within a liver hydatid cyst.

\section{Declaration of patient consent}

The authors certify that they have obtained all appropriate patient consent forms. In the form the patient(s) has/have given his/her/their consent for his/her/their images and other clinical information to be reported in the journal. The patients understand that their names and initials will not be published and due efforts will be made to conceal their identity, but anonymity cannot be guaranteed.

Financial support and sponsorship

Nil.

\section{Conflicts of interest}

There are no conflicts of interest.

\section{References}

1. Pedrosa I, Saíz A, Arrazola J, Ferreirós J, Pedrosa CS. Hydatid disease: Radiologic and pathologic features and complications. Radiographics 2000;20:795-817.

2. Paksoy Y, Odev K, Sahin M, Arslan A, Koç O. Percutaneous treatment of liver hydatid cysts: Comparison of direct injection of albendazole and hypertonic saline solution. AJR Am J Roentgenol 2005;185:727-34.

3. Botezatu C, Mastalier B, Patrascu T. Hepatic hydatid cyst-diagnose and treatment algorithm. J Med Life 2018;11:203-9.

4. Amalou H, Wood BJ. Beware catheter breakdown during alcohol sclerosis of lymphoceles. Cardiovasc Intervent Radiol 2014;37:850-1.

5. Nazarian GK, Myers TV, Bjarnason H, Stackhouse DJ, Dietz CA, Hunter DW. Applications of the Amplatz snare device during interventional radiologic procedures. AJR Am J Roentgenol 1995;165:673-8. 